\title{
A CONTAÇÃO DE HISTÓRIAS COMO PRÁTICA PEDAGÓGICA E INCLUSIVA NO ATENDIMENTO EDUCACIONAL ESPECIALIZADO: RELATO DE EXPERIÊNCIA COM ALUNOS COM DEFICIÊNCIA INTELECTUAL
}

\author{
STORY TELLING AS A PEDAGOGICAL AND INCLUSIVE \\ PRACTICE IN SPECIALIZED EDUCATIONAL SERVICE: \\ EXPERIENCE REPORT WITH STUDENTS WITH \\ INTELLECTUAL DISABILITIES
}

Luciana de Jesus Botelho Sodré dos Santos ${ }^{1}$

\begin{abstract}
RESUMO
Este artigo apresenta como objetivo compartilhar uma experiência com uso da contação de histórias para alunos com Deficiência Intelectual que frequentam a Sala de Recursos Multifuncionais para fazer o Atendimento Educacional Especializado - AEE, em uma escola da rede municipal de ensino de São Luís. A natureza deste estudo é um relato de experiência permeada de análises e discussões tecidas na relação: contação de histórias - prática inclusiva - alunos com Deficiência Intelectual, categorias levantadas e aprofundadas teoricamente por bibliografias nacionais e internacionais como: Coelho (2000), Abramovich (2002), Bettelheim (2002), Sartoretto e Bersh (2010), Vigotski (1997, 2007) dentre outros autores. Os resultados obtidos na aplicação dessa estratégia apontaram uma ampliação no vocabulário dos alunos, atenção, memória e concentração durante a realização das tarefas pós-contação denominadas de atividades geradoras, potencialização da oralidade, criatividade nas tarefas aplicadas envolvendo a escrita, interesse pelos livros e sobretudo, a interação social com os colegas e elevação da autoestima. Conclui que a utilização da contação de histórias como estratégia mediadora para o desenvolvimento cognitivo e funcional do aluno com Deficiência Intelectual no AEE é uma prática que se direciona tanto para a formação leitora como inclusiva desse aluno no contexto escolar, de vida e social de forma geral.

PALAVRAS-CHAVE: Atendimento Educacional Especializado. Contação de histórias. Deficiência Intelectual.
\end{abstract}

\begin{abstract}
This article to presente share an experience with the use of storytelling for students with Intellectual Disabilities who attend the Multifunctional Resource Room to provide Specialized Educational Service - SES, at a school in the São Luís municipal school system. The nature of this study is a report of experience permeated by analyzes and discussions woven into the relationship: storytelling - inclusive practice - students with Intellectual Disabilities, categories raised and deepened theoretically by national and international bibliographies such as: Coelho (2000), Abramovich (2002), Bettelheim (2002), Sartoretto and Bersh (2010), Vigotski $(1997,2007)$ among other authors. The results obtained in the application of this strategy pointed to an expansion in the students' vocabulary, increased attention, memory and concentration during the performance of postcounting tasks in the generating activities, potentiation of orality, creativity in
\end{abstract}

\footnotetext{
1 Mestra em Educação pela Universidade Estadual do Maranhão. Especialista em Educação Inclusiva, Educação Especial, Atendimento Educacional Especializado e Psicopedagogia. Professora do Atendimento Educacional Especializado nas redes pública de ensino estadual e municipal de São Luís, Maranhão. E-mail: prof.luciana.jbs@gmail.com. Orcid: https://orcid.org/0000-0002-8419-5559. Link do lattes: http://lattes.cnpq.br/2676229827334575.
} 
applied tasks involving writing, and interest in books and above all, social interaction with colleagues and raising self-esteem. It concludes that the use of storytelling as a mediating strategy for the cognitive and functional development of students with Intellectual Disabilities in the SES is a practice that is directed towards both reading and inclusive education of this student in the school, life and social context in general.

KEYWORDS: Storytelling. Specialized Educational Service. Intellectual Disability.

\section{INTRODUÇÃO}

A contação de histórias compreende uma das atividades mais remotas vistas na humanidade, pois desperta a imaginação, as emoções, o interesse e as expectativas do seu público ouvinte (crianças, jovens, adultos e idosos). É, por assim dizer, um método democrático e inclusivo que no ambiente escolar se congrega num processo contínuo de aprendizado contribuindo para a formação cidadã e crítica dos alunos.

Por meio dessa importante estratégia pedagógica, os alunos são estimulados a absorver valores morais e sociais, bem como desenvolver a criatividade, o gosto pela leitura e pela aprendizagem. Para os estudantes com deficiência, as histórias podem ser aliadas no processo de inclusão escolar.

O Atendimento Educacional Especializado (AEE), serviço da Educação Especial, previsto na Política Nacional de Educação Especial na Perspectiva da Educação Inclusiva, congrega atividades que incluem o lúdico, o acesso às formas diferenciadas de comunicação, a riqueza de estímulos nos aspectos físicos, emocionais, cognitivos, psicomotores, sociais e a convivência com as diferenças (BRASIL, 2008).

Assim, a contação de histórias além de ajudá-los no desenvolvimento cognitivo e potencializar a interação social, também pode ser utilizada como principal acesso na aprendizagem dos componentes curriculares do ensino regular.

$\mathrm{Na}$ escola, os alunos com Deficiência Intelectual geralmente se deparam com dificuldades no processo de aprendizagem, reprovações frequentes, baixa autoestima e, em alguns casos sentem-se desmotivados em participar assiduamente da escolarização, por não conseguir acompanhar o ritmo dos outros alunos ou mesmo por não serem incluídos em determinadas atividades.

Dessa forma, foram traçados os seguintes questionamentos para a busca de respostas: O que é a contação de histórias? Quais as contribuições para o aluno com Deficiência Intelectual no Atendimento Educacional Especializado? Como essa estratégia lúdica e pedagógica pode incitar nesses alunos o raciocínio, a linguagem e interpretações importantes para o acompanhamento dos componentes curriculares no ensino regular? 
Assim, o objetivo deste texto é compartilhar uma experiência com uso da contação de histórias para alunos com Deficiência Intelectual que frequentam a Sala de Recursos Multifuncionais para fazer o AEE, em uma escola da rede municipal de ensino de São Luís.

Portanto, pretende-se ainda analisar e discutir no transcorrer do relato de experiência, a relação da contação de histórias como estratégia que estimula o desenvolvimento cognitivo e a formação leitora desse respectivo aluno, bem como fomenta a Educação Inclusiva permitindo a esse aluno a utilização das próprias potencialidades nas diferentes situações da vida.

\section{A CONTAÇÃO DE HISTÓRIAS COMO UM ATO INCLUSIVO}

A contação de histórias caracteriza-se como uma prática secular, pois há muitos anos, foi e continua sendo desenvolvida como uma das mais antigas maneiras para o homem cultivar e compreender os valores praticados no convívio social e para entender as condutas que conduzem as comunidades em que se insere.

As histórias podem ser empregadas na educação para auxiliar os alunos a perceber o mundo ao seu redor. Elas imprimem valores morais, estimulam emoções, além de proporcionar o seu desenvolvimento leitor e cognitivo. Ouvir histórias, segundo Bello (2004, p. 159) “[...] pode tornar-se um encaminhamento para a construção da leitura".

O professor ao se utilizar da contação de histórias promoverá a inclusão na escola, pois incentivará os alunos a conhecerem o universo dos livros, ou seja, a terem um contato intenso com a sua língua e proporcionando a expansão do seu vocabulário, geralmente reduzido em decorrência da deficiência e pelas carências em serem constantemente estimulados. Em diálogo com Prieto (1999, p. 41):

[...] quando o professor se senta no meio de um círculo de alunos e narra uma história, na verdade, cumpre um desígnio ancestral. Nesse momento, ocupa o lugar do xamã, do bardo celta, do cigano, do mestre oriental, daquele que detém a sabedoria e o encanto, do porta-voz da ancestralidade e da sabedoria. Nesse momento ele exerce a arte da memória.

Constitui-se numa atividade fundamental que imprime conhecimentos e valores. A sua adoção no cotidiano das Salas de Recursos Multifuncionais durante o atendimento especializado traduz-se como determinante e expressivo para o desenvolvimento da aprendizagem.

Assim sendo, utilizá-la nesse contexto fomenta a inclusão para todos, pois serão instigados a imaginar e a criar. Para o professor, a maneira de conduzir didaticamente o 
atendimento especializado se tornará mais dinâmica e atrativa para o aluno, além de refletir positivamente num momento agradável, colaborativo e construtivo.

\section{E o aluno com deficiência intelectual nesse contexto?}

A Deficiência Intelectual é definida como “[...] um transtorno com início no período do desenvolvimento que inclui 'deficits' funcionais, tanto intelectuais como adaptativos, nos domínios conceitual, social e prático" (APA, 2014, p. 33).

Alunos com Deficiência Intelectual apresentarão dificuldades no raciocínio, solução de problemas, planejamento abstrato, juízo, aprendizagem de conteúdos curriculares, participação social e de vida independente (APA, 2014). Apesar de serem classificados como abaixo da média, em relação aos outros sem deficiência e da mesma idade não significa dizer serem incapazes.

Para fomentar o desenvolvimento cognitivo desse alunado compete ao professor a adoção de recursos e estratégias complementares para apoiá-los durante o processo educativo. Em consonância com os estudos de Vigotski (1997), no espaço educativo geralmente as incapacidades ou limitações são mais valorizadas, em detrimento da oferta de materiais diferenciados para proporcionar a superação das barreiras presente na cognição do aluno com Deficiência Intelectual.

É interessante destacar o conceito de Zona de Desenvolvimento Proximal (ZPD), posto por Vigotski (1997), cujo objetivo compreende em expandir a aprendizagem por intervenções que convertam as funções psicológicas superiores ${ }^{1}$. A ZPD, segundo descreve o respectivo autor é definida como a distância entre o desenvolvimento real e potencial. Em que o desenvolvimento real será tudo aquilo que o sujeito consegue fazer com independência e o desenvolvimento potencial, compreenderá o que ele consegue fazer com auxílio dos outros.

Para Vigotski (1997) existe um imperativo de serem estabelecidas estratégias mais interessantes para fomentar o desenvolvimento cognitivo para indivíduos com Deficiência Intelectual, pois estes não devem ser entendidos com menos desenvolvidos que os outros, mas como sujeitos que se desenvolvem de forma qualitativamente diferente.

[...] é nas relações que os sujeitos conhecem, apropriam-se do que os define socialmente, do que os diferencia. Nas relações convertem em próprias as ideias que circulam socialmente e, assim, vão se constituindo sujeitos: 'apreendem' a si mesmos e ao mundo em torno deles, desestabilizando, dessa forma, a tese de que não aprendem e, nesse processo, os modos de funcionamento psíquico - cognição, imaginação e emoção - articulam-se de forma interconstitutiva, resultando na emergência do sujeito, de sua subjetividade (CARVALHO, 2006, p. 5).

\footnotetext{
${ }^{1}$ Conforme Oliveira (2002) o funcionamento superior está ligado ao fator orgânico e deriva das possibilidades de compensação concretizadas pelo grupo social.
} 
Então, ao se direcionar múltiplas atividades, estratégias e recursos para alunos com Deficiência Intelectual, há de se considerar as suas reais possibilidades e necessidades. Conforme propõem Sartoretto e Bersch (2010, p. 37) antes de direcionar qualquer ação para esse aluno, faz-se interessante considerar os seguintes pontos:

Quem é o aluno com Deficiência Intelectual?

Quais são as suas principais habilidades manifestadas?

Quais são as necessidades específicas desse aluno, decorrentes da deficiência e/ou impostas pelo ambiente familiar?

Como está organizado o plano pedagógico do professor da sala comum?

Quais barreiras existem quanto à participação e ao aprendizado do aluno nas tarefas escolares?

Os materiais pedagógicos utilizados pelo aluno são adequados?

Deste modo, não se deve focar somente nos 'deficits', mas sim nas reais perspectivas do aluno com Deficiência Intelectual, pois estes alunos demonstram muitas habilidades, que às vezes passam desapercebidas pelos docentes no contexto de ensino quando não se reflete sobre as condições desses sujeitos como sugerem Sartoretto e Bersch (2010).

\section{UM (RE) INVENTAR NO AEE: CONTANDO HISTÓRIAS PARA UM APRENDIZADO INCLUSIVO}

O Atendimento Educacional Especializado (AEE) é um serviço da Educação Especial $^{2}$ o qual compete direcionar ações para ocorrer o desenvolvimento do aluno com deficiência, tanto nos aspectos cognitivos como funcionais, além da garantia de participação e acesso para fomento a inclusão no ensino regular.

No caso da deficiência intelectual [...] O educador precisa privilegiar suas potencialidades e talentos, recusando a suposição de limites para o que pode ser alcançado. Mesmo nas limitações intelectuais muito graves, é possível manter uma concepção prospectiva e a diretriz de mobilização de forças compensatórias, partindo de atuações em que o outro faz pelo aluno o que ela não pode fazer (KOHL; REGO; SOUZA, 2002, p. 102-103).

O professor ao dinamizar o AEE com a utilização da contação de histórias estar-se-á contribuindo para que o aprendizado inclusivo se mantenha concreto, dinâmico e motivador para o aluno. Em concordância com Omote (2006, p.261):

No enfrentamento do desafio de escolarizar alunos deficientes em classes de ensino comum tem sido apontado o ensino individualizado, adequando as atividades, estratégias e eventualmente até parte dos objetivos às particularidades de cada aluno com necessidades educacionais especiais.

\footnotetext{
${ }^{2}$ Modalidade de ensino transversal a todos os níveis e etapas da Educação Básica (BRASIL, 2001).
} 
Existem inúmeras vantagens e possibilidades que a contação de histórias pode proporcionar, particularmente para o aluno com Deficiência Intelectual além da sua inclusão no mundo do conhecimento e no contexto social.

[...] proporcionar o acesso democrático ao livro e à leitura no cotidiano de crianças e adolescentes [...] consiste em promover a formação de leitores, a cidadania e a ampliar o público leitor de forma prazerosa, numa ação sistemática e continuada, por meio das atividades desenvolvidas por atores, escritores e contadores de histórias (ROCHA, 2007, p. 33).

Dessa forma, o professor especializado ou Professor do $\mathrm{AEE}^{3}$ precisa compreender que o conhecimento está em constante evolução. Técnicas, estratégias e recursos precisam de adequação e adaptação. Apesar de a contação de histórias ser um método secular e positivo para a aprendizagem, prescinde de adequação seja qual for a necessidade. E quando empregado de maneira adequada, os resultados são os promissores.

\section{Um caminho a percorrer: procedimentos metodológicos}

A experiência foi desenvolvida em uma escola da rede pública municipal de ensino de São Luís, Maranhão, que possui Sala de Recursos Multifuncionais com o Atendimento Educacional Especializado (AEE). Está localizada na região central de São Luís, cujo núcleo educacional $^{4}$ a qual pertence é o Centro.

Funciona nos turnos diurno e noturno oferendo ensino fundamental com os anos iniciais e finais, e as modalidades de ensino como a Educação de Jovens e Adultos, e a Educação Especial com o AEE.

Convém pontar que o AEE é oferecido nos turnos matutino e vespertino na respectiva escola. Em cada turno existe um profissional especializado para atender os alunos públicoalvo da Educação Especial ${ }^{5}$. Esse atendimento é ofertado para o aluno no turno inverso ao qual estuda na sala comum de ensino (BRASIL, 2008). Conforme o Decreto n. 7.611/2011, o AEE apresenta como objetivos:

\footnotetext{
I - prover condições de acesso, participação e aprendizagem no ensino regular e garantir serviços de apoio especializados de acordo com as necessidades individuais dos estudantes;

II - garantir a transversalidade das ações da educação especial no ensino regular;

III - fomentar o desenvolvimento de recursos didáticos e pedagógicos que eliminem as barreiras no processo de ensino e aprendizagem;
}

\footnotetext{
${ }^{3}$ Definição expressa pela Resolução n. 04/2009.

${ }^{4}$ A Secretaria Municipal de Educação de São Luís-MA (SEMED) organiza e distribui as escolas e seus anexos em sete núcleos: Anil, Centro, Coroadinho, Itaqui Bacanga, Turu-Bequimão, Rural e Cidade Operária (PREFEITURA DE SÃO LUÍS, 2020).

5 Compreendem os alunos com deficiência (física, intelectual, auditiva, surdocegueira, múltipla e visual), Transtornos Globais do Desenvolvimento (TGD) e altas habilidades/superdotação (BRASIL, 2008).
} 
IV - assegurar condições para a continuidade de estudos nos demais níveis, etapas e modalidades de ensino.

Dando prosseguimento, os sujeitos envolvidos nas atividades de contação de histórias foram 5 (cinco) alunos com Deficiência Intelectual ${ }^{6}$ que cursam respectivamente o $4 .^{\circ}, 5 .^{\circ}$ e 6. ${ }^{\circ}$ ano do ensino fundamental. Foram selecionados por ser um público mais numeroso no AEE desta escola e principalmente pelas dificuldades acentuadas na leitura e escrita. Eles estudam na sala comum de ensino no turno vespertino e no turno matutino frequentam o AEE na Sala de Recursos Multifuncionais ${ }^{7}$ da escola.

A contação de histórias e suas atividades entraram no Plano de Atendimento Educacional Especializado ${ }^{8}$ desses alunos, após um período de observação nos estilos de aprendizagem, necessidades, potencialidades, gostos e preferências, entre outras reações dos alunos. Com relação, aos estilos de aprendizagem, a respectiva Teoria ${ }^{9}$ para Barros (2008, p.19):

[...] não tem por objetivo medir os estilos de cada indivíduo e rotulá-lo de forma estagnada, mas, identificar o estilo de maior predominância na forma de cada um aprender e, com isso, elaborar o que é necessário desenvolver nesses indivíduos, em relação aos outros estilos não predominantes. O objetivo é ampliar as capacidades dos indivíduos para que a aprendizagem seja um ato motivador, fácil, comum e cotidiano.

Além disso, as avaliações dos professores do ensino regular foram muito úteis, pois eles revelaram os seus desafios no ensino da leitura e componentes curriculares para aluno com Deficiência Intelectual, de modo que estes associem como significativo.

Diante dessa situação, o Professor do AEE planejará ações que visem auxiliar o professor do ensino regular na aprendizagem do aluno com deficiência, competindo particularmente ao profissional especializado a seguinte atribuição:

[...] estabelecer articulação com os professores da sala de aula comum, visando à disponibilização dos serviços, dos recursos pedagógicos e de acessibilidade e das estratégias que promovem a participação dos alunos nas atividades escolares (BRASIL, 2009).

\footnotetext{
${ }^{6}$ Foram resguardadas as identidades dos alunos (nomes e rosto nas fotos) em cumprimento a Resolução n. $510 / 2010$.

${ }^{7}$ Espaço físico, com mobiliários, materiais didáticos, recursos pedagógicos e de acessibilidade e equipamentos específicos onde é realizado o AEE (BRASIL, 2009).

${ }^{8}$ Consiste num documento elaborado pelo Professor do AEE, após um processo de avaliação das de cada aluno. Engloba ainda identificação das necessidades educacionais específicas e potencialidades, definição dos recursos e objetivos necessários e das atividades a serem desenvolvidas (SANTOS, 2019; BRASIL, 2009).

${ }^{9}$ Correspondem às preferências e tendências altamente individualizadas de uma pessoa, que influem em sua maneira de apreender um determinado conteúdo. Existem quatro estilos definidos: o ativo, o reflexivo, o teórico e o pragmático (BARROS, 2008; ALONSO E GALLEGO, 2008).
} 
Após as devidas constatações, tais ações foram realizadas no período de agosto a dezembro do ano de 2019. Os principais procedimentos que envolveram a aplicação da contação de histórias para esse alunado perpassaram pelas seguintes etapas:

I. Observação do aluno com Deficiência Intelectual para descrição do seu perfil, considerando seus estilos de aprendizagem, avaliações apontadas pelo professor do ensino comum, relatórios da escola e informações dos familiares dos alunos;

II. Organização do espaço, definição do dia da semana e horários para a contação de histórias;

III. Seleção das histórias com uma linguagem mais próxima do cotidiano dos alunos, priorizando o concreto e que trabalhassem conteúdos curriculares;

IV. Adequação no texto de histórias que demandariam um tempo maior de contação para um tempo menos prolongado e no vocabulário que estavam com palavras desconhecidas ou complexas para os alunos;

V. Elaboração de recursos e atividades geradoras para o pós-contação;

VI. Apresentação da proposta à direção da escola, coordenação pedagógica, aos professores, familiares responsáveis pelos alunos e profissionais da Superintendência da Área da Educação Especial da Secretaria Municipal de Educação de São Luís (SAEE) que atuam no acompanhamento do AEE nas escolas da rede municipal de ensino, com objetivo de socialização;

VII. Execução da contação de histórias e aplicação das atividades com o conteúdo de cada história contada para associação e estímulo a aprendizagem.

Convém pontuar que nos meses de agosto e setembro foram realizadas as etapas I, II, III, IV, V e VI. A etapa VII foi aplicada nos meses de outubro, novembro e dezembro de 2019.

\section{RESULTADOS OBSERVADOS}

Foram organizadas 10 (dez) dez sessões com duração de 2 (duas) horas, resultando um total de 20 (vinte) horas de histórias contadas e atividades aplicadas, desenvolvidas no turno matutino, que seguiram os procedimentos exibidos no Quadro 1 abaixo:

\begin{tabular}{|c|c|c|}
\hline $\begin{array}{c}\text { Meses e } \\
\text { Dias }\end{array}$ & Horário & Descrição \\
\hline \begin{tabular}{l|l}
10.10 \\
17.10 \\
24.10 \\
31.10
\end{tabular} & $8 \mathrm{~h}$ às $10 \mathrm{~h}$ & $\begin{array}{l}\text { - Boas-vindas com o espaço organizado e preparado para receber os alunos; } \\
\text { - Apresentação do livro, bem como da história a ser contada (autor, editora, ano } \\
\text { de publicação, ilustrações entre outros itens); } \\
\text { - Questionamentos iniciais aos alunos: vocês conhecem essa história? O que }\end{array}$ \\
\hline
\end{tabular}


A Contação de Histórias Como Prática Pedagógica e Inclusiva no Atendimento Educacional Especializado: Inclusiva no Atendimento Educacional Especializado: Relato de Experiência com Alunos com Deficiência Intelectual

\begin{tabular}{|c|c|c|}
\hline 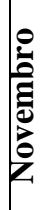 & $\begin{array}{l}07.11 \\
14.11 \\
21.11 \\
28.11\end{array}$ & $\begin{array}{l}\text { - Contação da história de forma objetiva e concreta com objetos disponíveis na } \\
\text { "Caixa Mágica das Histórias" } \\
\text { - No final da contação o aluno é convidado a conhecer todos os objetos usados } \\
\text { da caixa; }\end{array}$ \\
\hline 党 & $\begin{array}{l}05.12 \\
12.12\end{array}$ & $\begin{array}{l}\text { - Questionamentos pós-contação da história: vocês gostaram? O que mais } \\
\text { gostaram? Querem ouvir de novo? } \\
\text { - Aplicação de atividades geradoras de forma dinâmica e diversificada para } \\
\text { incentivo à leitura e escrita sobre a história de cunho prático. }\end{array}$ \\
\hline
\end{tabular}

Fonte: produção da autora com dados da intervenção (2019).

Reitera-se que no Atendimento Educacional Especializado os alunos são atendidos seguindo um cronograma de dias e horários diferenciados. Geralmente na escola, os alunos são atendidos entre duas e três vezes por semana na Sala de Recursos Multifuncionais com duração de 2 (duas) horas por atendimento. Esses atendimentos são coletivos e individuais, ou seja, o aluno pode ser atendido de maneira individualizada ou coletivamente em grupo com os outros colegas.

O dia da semana ideal para todos os alunos foi a quinta-feira, que passou a se denominar de "Quinta da História". Houve a necessidade de ajustar o horário dos alunos para que todos estivessem juntos no mesmo horário e, assim participassem coletivamente desse momento dinâmico e enriquecedor.

Após diálogo com os familiares e coordenação pedagógica da escola sobre os horários, foi dado início a contação de histórias no dia da semana acima estabelecido (quinta-feira). Foram selecionadas e utilizadas as seguintes narrativas e atividades geradoras, conforme detalha o Quadro 2 a seguir:

Quadro 2 - Narrativas e atividades geradoras utilizadas

\begin{tabular}{|c|c|c|c|}
\hline Livro & Autor & Temática da história & Atividades propostas \\
\hline $\begin{array}{l}\text { 1. Um mundo } \\
\text { melhor }\end{array}$ & Patrício Dugnani & $\begin{array}{l}\text { Educação } \\
\text { Preservação do meio ambiental; }\end{array}$ & $\begin{array}{l}\text { Jogo da trilha da história } \\
\text { Desenho Livre }\end{array}$ \\
\hline $\begin{array}{l}\text { 2. Turma do } \\
\text { Utilixo }\end{array}$ & $\begin{array}{l}\text { Nely A. Guernelli } \\
\text { Nucci }\end{array}$ & $\begin{array}{l}\text { Educação Ambiental; Coleta } \\
\text { Seletiva }\end{array}$ & $\begin{array}{l}\text { Praticando a Coleta seletiva: uso } \\
\text { de coletores } \\
\text { Atividades de pintura }\end{array}$ \\
\hline $\begin{array}{l}\text { 3. Donana e } \\
\text { Titonho }\end{array}$ & Ninfa Parreiras & $\begin{array}{l}\text { Educação } \\
\text { Reciclagem }\end{array}$ & $\begin{array}{l}\text { Recorte e colagem } \\
\text { Desenho Livre }\end{array}$ \\
\hline $\begin{array}{l}\text { 4. Faça novas } \\
\text { amizades }\end{array}$ & $\begin{array}{l}\text { Quixot } \\
\text { Publications }\end{array}$ & Socialização; Amizade & $\begin{array}{l}\text { Amigo Secreto } \\
\text { Dado Maluco }\end{array}$ \\
\hline $\begin{array}{l}\text { 5. O menino } \\
\text { que via com } \\
\text { as mãos }\end{array}$ & $\begin{array}{l}\text { Alexandre } \\
\text { Azevedo }\end{array}$ & Inclusão social & $\begin{array}{l}\text { Cruzadinhas } \\
\text { Desenho livre }\end{array}$ \\
\hline 6. Manias & Lúcia Reis & Ensino Religioso & Bingo da interpretação da história \\
\hline $\begin{array}{l}\text { 7. Cozinheiro } \\
\text { atrapalhado }\end{array}$ & Silvio Costta & $\begin{array}{l}\text { Educação Física; Lateralidade; } \\
\text { Percepção Visual }\end{array}$ & $\begin{array}{l}\text { Caça-palavras cultural } \\
\text { Desenho Livre }\end{array}$ \\
\hline $\begin{array}{l}\text { 8. Tabuleiro da } \\
\text { baiana }\end{array}$ & $\begin{array}{l}\text { Elma Maria } \\
\text { Fonseca de Lima }\end{array}$ & Geografia; Cultura brasileira & Dominó gigante da história \\
\hline $\begin{array}{l}\text { 9. Sítio do Tio } \\
\text { Chico }\end{array}$ & $\begin{array}{ll}\text { Nair } & \text { Medeiros } \\
\text { Barbosa } & \end{array}$ & $\begin{array}{l}\text { Ciências; Produção e matéria- } \\
\text { prima com recursos naturais }\end{array}$ & $\begin{array}{l}\text { Bingo cultural } \\
\text { Desenho livre }\end{array}$ \\
\hline
\end{tabular}




\begin{tabular}{|c|l|l|l|}
$\begin{array}{c}\text { 10. ABC do } \\
\text { dromedário }\end{array}$ & $\begin{array}{l}\text { Alexandre } \\
\text { Azevedo }\end{array}$ & $\begin{array}{l}\text { Alfabeto; Características e } \\
\text { particularidades de animais, } \\
\text { nomes de cidades, objetos, } \\
\text { hábitos alimentares }\end{array}$ & $\begin{array}{l}\text { Recorte e colagem } \\
\text { Desenho Livre }\end{array}$ \\
\hline
\end{tabular}

Fonte: produção da autora com dados da intervenção (2019).

Essa escolha foi organizada cautelosamente e com objetivos previamente definidos. Adotou-se como ponto de partida a possibilidade do contingente de alunos envolvidos, bem como na abrangência espacial e na variedade de atividades realizadas.

[...] o cuidado que o contador dispensa para a contação não é menor que o cuidado dispensado à escolha das histórias, haja vista a necessidade de os temas serem adequados à idade do ouvinte e aos seus interesses, para que o objetivo, (despertar o gosto pela leitura e formar leitores), seja alcançado (ABRAMOVICH, 2002, p. 16).

Nos três primeiros dias do mês de outubro, os alunos estavam um pouco retraídos, tímidos, distraindo-se com facilidade. Em alguns momentos não compreenderam o contexto da história. Então, houve a necessidade de repetir a contação, mais pausadamente. Nas atividades aplicadas não sentiram dificuldades, mas precisaram de apoio para conduzi-los passo a passo. Com os colegas a interação foi iniciada, mas alguns não interagiram.

Essa situação é explicada, pois, não basta apenas escolher um livro e contar uma história, mas analisar o perfil do aluno, até onde vai o seu nível de compreensão, adequar a linguagem da história para o concreto. Em acordo com Honora e Frizanco, (2008, p. 107):

Não existem 'receitas' prontas para o trabalho com alunos tanto com deficiência intelectual, ou com outra deficiência, quanto com os sem deficiência. Devemos ter em mente que cada aluno é um e que as suas potencialidades, necessidades e conhecimentos ou experiências prévias devem ser levados em conta, sempre.

Diante disso, recorreu-se a construção de uma caixa com vários objetos presentes no texto das histórias de modo a aproximar o sentido da linguagem ao mais próximo do real. A caixa foi intitulada "Caixa Mágica das Histórias", recurso esse que funcionou como um reforço a mais para a atenção dos alunos.

No momento que se pronunciava o nome de um determinado objeto presente na cena da história, mais sentido a esta era atribuída, pois, para aluno além de ouvir, participar da contação deixa o ato mais dinâmico pegando os objetos.

O professor se torna um organizador efetivo da situação de aprendizagem, na qual ele reconhece, afirma e apoia as oportunidades para a criança aprender à sua própria maneira, no seu próprio nível e a partir das suas experiências passadas (MOYLES, 2002, p.101).

Nos demais dias do mês de outubro e novembro percebeu-se uma animação e expectativa para a "Quinta da História". Os alunos já chegavam na Sala de Recursos 
Multifuncionais questionando: "tia vou ouvir tudo hoje"; "quero abrir a caixa", "cadê os livros", "quero ajuda na tarefa" e dentre outros pronunciamentos.

Percebeu-se que a contação estava sendo significativa para eles, pois perguntavam sobre os livros, sobre a caixa. Tal situação remete ao entendimento de que os alunos são mais atuantes e aprendem, segundo Fusari (2003, p.161):

[...] nas relações comunicacionais cotidianas, a conservar ou a transformar aspectos da realidade e da imaginação sobre a vida e sobre a sua história, partilhados com múltiplos textos de comunicação visuais, sonoros, audiovisuais, verbais [...] e com pessoas da sua familiaridade, inclusive professores.

Com relação à aprendizagem de conteúdos curriculares, os professores do ensino regular relataram que em sala de aula eles estavam jogando o papel no cesto e avisavam que na história da "tia" da Sala de Recursos todos jogavam o lixo no cesto para o meio ambiente "ficar limpo". Algumas histórias selecionadas tratavam do tema Educação Ambiental, por isso, a reação dos alunos e da professora. Para Coelho (2000, p.15) “[...] a literatura, em especial a infantil, tem uma tarefa fundamental a cumprir nesta sociedade em transformação: a de servir como agente de formação, seja no convívio leitorllivro, seja no diálogo leitorltexto estimulado pela escola".

Fotos 1 e 2 - Materiais utilizados para contação de histórias que tratam da Educação Ambiental

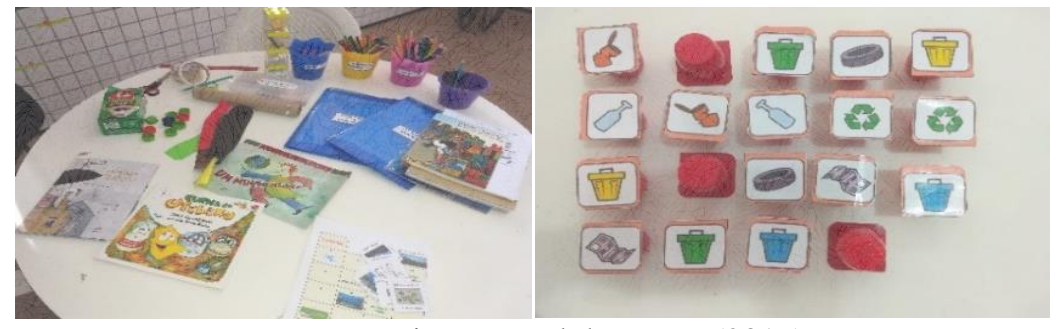

Fonte: arquivo pessoal da autora (2019).

Fotos 3 e 4 - Alunos realizando atividades após a contação de histórias

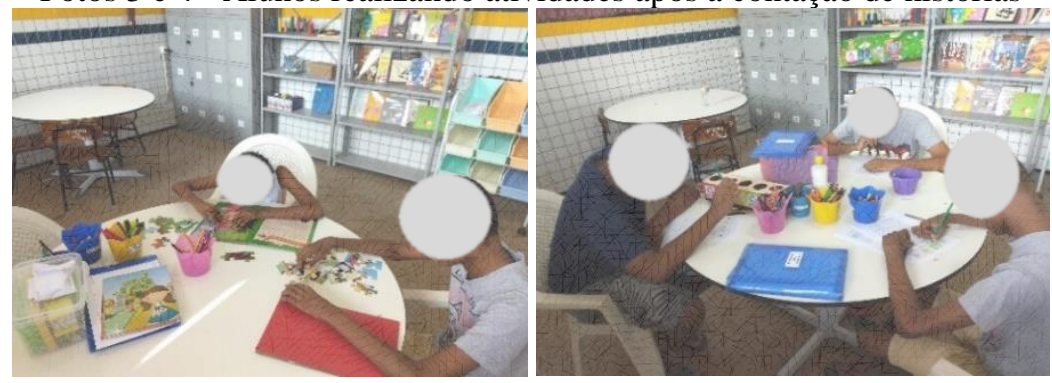

Fonte: arquivo pessoal da autora (2019).

Gradualmente os alunos foram se apropriando de algo abordado na contação de histórias, como o próprio vocabulário. Antes alguns alunos não sabiam o que eram e para que serviam os coletores da coleta seletiva e nem o próprio nome "coletor". Percebeu-se que eles 
começaram a identificar as cores e associar a categoria de resíduo (lixo) que deveriam colocar em cada coletor.

[...] como a criança e o jovem em cada momento da sua vida está exposta à sociedade em que vive, certamente aprenderá a enfrentar as condições que lhe são próprias, desde que os seus recursos interiores o permitam [...] a criança e o jovem adéquam o conteúdo inconsciente às fantasias consciente, o que a capacita a lidar com este conteúdo (BETTELHEIM, 2002, p. 5-8).

Destaca-se também a interação social entre eles, principalmente com a contação da história "Faça novas amizades", que trata justamente da aceitação e novas amizades. Quando algum colega faltava ou chegava com atraso, eles perguntavam: “tia, o Marcos ${ }^{10}$ está doente?". Para eles foi internalizado que quando alguém atrasa ou não vem é sinônimo de doença.

A partir desse contexto explicou-se quem nem sempre isso acontece. O colega pode ter acompanhado os pais para algum compromisso. Então, essa preocupação com a ausência do outro foi algo que chamou a atenção, pois demonstra que garantidamente a contação de histórias está sendo significativa para esses alunos.

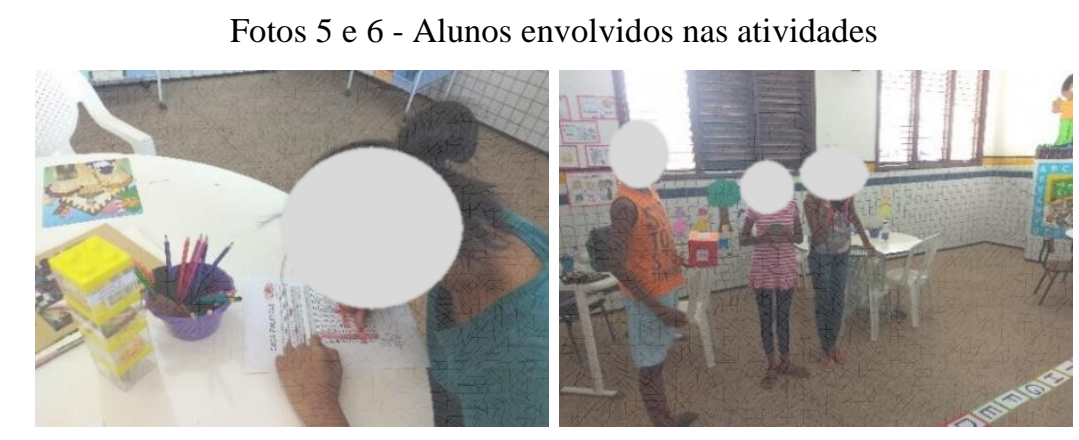

Fonte: arquivo pessoal da autora (2019).

Portanto, os resultados analisados demonstram que a contação de histórias para os alunos com Deficiência Intelectual foi significativa e possibilitou além do desenvolvimento da área cognitiva, das áreas motora e afetiva-social. E abriu caminho para se pensar em mais possibilidades pedagógicas e inclusivas como projetos que incluam os outros alunos públicoalvo da Educação Especial.

\section{CONSIDERAÇÕES FINAIS}

A contação de histórias é uma estratégia pedagógica que trabalha a prática formativa para a leitura e para a inclusão, sendo entendida como uma necessidade pensada para atender à diversidade de estilos de aprendizagem dos alunos no contexto do Atendimento Educacional

\footnotetext{
${ }^{10}$ Nome fictício.
} 
Especializado. Essa questão foi levantada como necessária, pois, os resultados conquistados demostraram que a contação de histórias enquanto prática secular, despertou nos alunos a autoconfiança para a aprendizagem, a contribuição para o desenvolvimento intelectual e para a participação assídua nas atividades pós-contação (atividades geradoras). Os objetivos propostos com uso da contação de histórias foram alcançados, pois, pensar em estratégia que proporcionem o aprendizado e o desenvolvimento cognitivo dos alunos com deficiência são uteis e significativos, desde que sejam pensadas para eles, focando suas necessidades e potencialidades. Logo, a contação de histórias é um momento em que o professor estabelece com o aluno um clima de reciprocidade. Após ouvir uma história, o ideal é proporcionar o seu prolongamento com a inclusão de tarefas dinâmicas e não maçantes, pois o entusiasmo dos alunos participantes deste momento criativo, no AEE, pelas atividades realizadas foi um fator decisivo para se refletir a possibilidade de elaborar uma ação na escola de forma que estes alunos sejam percebidos como sujeitos com potencial. Esta sugestão confirma o valor da contação de história para desenvolver o hábito da leitura e como fonte de prazer, conhecimento e caminho para a inclusão escolar.

\section{REFERÊNCIAS}

ABRAMOVICH, F. Literatura Infantil: gostosuras e bobices. São Paulo: Scipione, 2002.

ALONSO, C. M.; GALLEGO, D. J.; HONEY, P. Los estilos de aprendizaje: procedimientos de diagnóstico y mejora. Madrid, ES: Mensajero, 2002.

APA - AMERICAN PSYCHIATRIC ASSOCIATION. Manual de Diagnóstico e Estatística de Transtornos Mentais: DSM 5. Tradução de Maria Inês Corrêa Nascimento. 5 ed. Porto Alegre: Artmed, 2014.

AZEVEDO, A. ABC do dromedário. 3 ed. São Paulo: Paulinas, 2011.

AZEVEDO, A. O menino que via com as mãos. E ed. São Paulo: Paulinas, 2007. BARBOSA, N. M. Sítio do Tio Chico. 12 ed. São Paulo: Paulinas, 2013.

BARROS, D. M. V. A Teoria dos estilos de aprendizagem: convergência com as tecnologias digitais. Revista SER: Saber, Educação e Reflexão, Agudos, SP, v.1, n.2, p. 14-28, jul./dez., 2008.

BELLO, S. Por que devemos contar histórias na escola? In: GIRARDELLO, G. (org.). Baús e chaves da narração de histórias. Florianópolis, SC: SESC, 2004. p. 156-163.

BETTELHEIM, B. A psicanálise dos contos de fada. 16. ed. Rio de Janeiro: Paz e Terra, 2002.

BRASIL. Decreto n. 7.611, de 17 de novembro de 2011. Dispõe sobre a educação especial, o atendimento educacional especializado e dá outras providências. Diário Oficial da União: seção 1, Brasília, DF, 18 nov. 2011. 
BRASIL. Ministério da Educação. Secretaria de Educação Especial. Política Nacional de Educação Especial na Perspectiva da Educação Inclusiva. Brasília, DF, 2008.

BRASIL. Ministério da Educação. Secretaria de Educação Especial. Sala de Recursos Multifuncionais: espaço para atendimento educacional especializado. Brasília: 2006.

BRASIL. Ministério da Saúde. Conselho Nacional de Saúde. Resolução n. 510, de 7 de abril de 2016. Trata sobre as diretrizes e normas regulamentadoras de pesquisa em ciências humanas e sociais. Diário Oficial da União: seção 1, Brasília, DF, 24 maio 2016.

BRASIL. Resolução n. 2, de 11 de setembro de 2001. Institui Diretrizes Nacionais para a Educação Especial na Educação Básica. Diário Oficial da União: seção 1, Brasília, DF, p. 39-40, 14 set. 2001.

BRASIL. Resolução n. 4, de 2 de outubro de 2009. Institui Diretrizes Operacionais para o Atendimento Educacional Especializado na Educação Básica, modalidade Educação Especial. Diário Oficial da União: seção 1, Brasília, DF, p. 17, 5 out. de 2009.

BRAUN, P.; NUNES, L. R. D. de P. A Formação de Conceitos em Alunos com Deficiência Intelectual: o Caso de Ian. Rev. Bras. Ed. Esp., Marília, SP, v. 21, n. 1, p. 75-92, jan. mar., 2015.

CARVALHO, M.F. Educação de jovens e adultos com deficiência mental: inclusão escolar e constituição dos sujeitos. Horizontes, Itatiba, SP, v. 24, n. 2, p. 161-171, 2006.

COELHO, N. N. A literatura infantil: abertura para formação de uma nova mentalidade. In: . Literatura infantil: teoria - análise - didática. São Paulo: Moderna, 2000. p.14-

32.

COSTTA, S. Cozinheiro atrapalhado. 1 ed. São Paulo: Paulinas, 2011.

DUGNANI, P. Um mundo melhor. 9 ed. São Paulo: Paulinas, 2017.

HONORA M.; FRIZANCO, M. L. Esclarecendo as deficiências: aspectos teóricos e práticos para contribuir com uma sociedade inclusiva. Ciranda Cultural, SP, 2008.

KOHL, M.O.; REGO, T.C.; SOUZA, D.T.R. (org.). Psicologia, educação e as temáticas da vida contemporânea. São Paulo: Moderna, 2002.

LIMA, E. M. F. de. Tabuleiro da baiana. 1 ed. São Paulo: Paulinas, 2015.

MOYLES, J. R. Só brincar? O papel do brincar na educação infantil. Tradução de Maria Adriana Veronese. Porto Alegre: Artmed, 2002.

NUCCI, N. A. G. Turma do Utilixo. 17 ed. São Paulo: Paulinas, 2015.

OLIVEIRA, B.O. et al. O brincar e a criança do nascimento aos seis anos. Petrópolis: Vozes, 2002.

OMOTE, S. Inclusão e a questão das diferenças na educação. Perspectiva, Florianópolis, SC, v. 24. n. Especial, p. 251-272, jul./dez., 2006. 
PARREIRAS, N. Donana e Titonho. 1 ed. São Paulo: Paulinas, 2018.

PREFEITURA DE SÃO LUÍS. Secretaria Municipal de Educação. A Secretaria. 2020. Disponível em: https://www.saoluis.ma.gov.br/semed/conteudo/74. Acesso em: 01 set. 2020.

PRIETO, H. Quer ouvir uma história: Lendas e mitos no mundo da criança. São Paulo: Angra,1999.

QUIXOT PUBLICATIONS. Faça novas amizades. Tradução de Klaus Heinrich Georg Rehfeldt. Blumenau, SC: Todolivro Editora, 2015.

REIS, L. Manias. São Paulo: Paulinas, 2015.

FUSARI, M F R. Brincadeiras e brinquedos na TV para crianças: mobilizando opiniões de professores em formação inicial. In: KISHIMOTO T. M. (org.). Jogo, brinquedo, brincadeira e a educação. 7 ed. São Paulo: Cortez, 2003.

ROCHA, E. T. C. Leitura e cidadania: a experiência de Goiabeiras. 2007. Monografia (Especialização em Leitura e Produção Textual) - Universidade Federal do Espírito Santo, Vitória, ES. 2007.

SANTOS, L. de J. B. S. dos. Planejamento da ação didática na Educação Especial: compreensões necessárias na elaboração do plano de AEE. Revista Ciências Humanas UNITAU, Taubaté, SP, v. 12, n. 1, ed. 23, p. 98 - 113, jan./abr., 2019.

SARTORETTO, M. L.; BERSH, R. A educação especial na perspectiva da educação na perspectiva da inclusão escolar: recursos pedagógicos acessíveis e Comunicação Aumentativa e Alternativa. Brasília: MEC; SEESP; UFCE, 2010.

VIGOTSKI, L.S. A formação da mente: o desenvolvimento dos processos psicológicos superiores. 7. ed. São Paulo: Martins Fontes, 2007.

VIGOTSKI, L.S. Obras escogidas V: Fundamentos de defectología. Madrid: Visor, 1997.

Artigo Recebido: 27 de março de 2021.

Artigo Aceito: 11 de maio de 2021. 